\title{
Regras Institucionais e Concentração de Beneficiários de Bolsas de Iniciação Científica Distribuídas entre Discentes da Universidade de Brasília
}

\author{
http://dx.doi.org/10.21527/2237-6453.2020.54.353-365
}

Recebido em: $26 / 7 / 2020$

Aceito em: $28 / 10 / 2020$

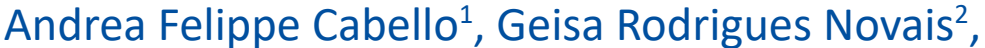 \\ André Nunes², Celso Vila Nova de Souza Junior ${ }^{2}$
}

\begin{abstract}
RESUMO
O estudo tem como propósito a análise da concentração de beneficiários do Programa de Iniciação Científica (ProlC) - por docente orientador e unidades acadêmicas da Universidade de Brasília (UnB) de 2004 a 2018. Apresenta-se uma análise por meio do Índice de Herfindahl-Hirschman $(\mathrm{HH})$. O índice é frequentemente utilizado para verificar a concentração industrial, mas adaptado para o contexto de uma instituição de ensino. O propósito é investigar o alcance e uso do Programa de Iniciação Científica na UnB como ferramenta de incentivo à pesquisa de forma transversal a todas as áreas de conhecimento. Os resultados indicam que a concentração média não é elevada. Ao, no entanto, avaliar os índices por ano, percebem-se padrões distintos e a influência de instrumentos institucionais utilizados para selecionar os participantes do programa.
\end{abstract}

Palavras-chave: Efeitos do Programa de Iniciação Científica. Concentração. Índice de Herfindahl-Hirschman.

\section{INSTITUTIONAL RULES AND CONCENTRATION OF BENEFICIARIES OF SCIENTIFIC INITIATION SCHOLARSHIPS DISTRIBUTED AMONG STUDENTS OF THE UNIVERSITY OF BRASÍLIA}

\section{ABSTRACT}

The purpose of the study is to analyze the concentration of beneficiaries of the Program for Scientific Initiation (ProlC) - or Undergraduate Research incentive program - by Professors and Departments at the University of Brasília (UnB) from 2004 to 2018. We use a Herfindahl-Hirschman (HH) index. Index often used for industrial concentration, but adapted to the context of an educational institution. Our purpose is to investigate its reach and use as an incentive to research in a broad way that reaches all fields of expertise. The results indicate that the average concentration is not high. However, when assessing the indexes by year, different patterns and the influence of institutional instruments used to select the participants of the program is perceived.

Keywords: Scientific Research Undergraduate Incentive Program Effects. Concentration. Herfindahl-Hirschman Index.

\footnotetext{
${ }^{1}$ Autora correspondente. Universidade de Brasília (UnB). Campus Darcy Ribeiro - Asa Norte. CEP 70910-900. Brasília/DF, Brasil. http://lattes. cnpq.br/4731226594888669. http://orcid.org/0000-0003-1489-0676. andreafc@gmail.com
}

${ }^{2}$ Universidade de Brasília (UnB). Brasília/DF, Brasil. 
A Iniciação Científica insere-se no Ensino Superior por meio da vinculação entre o ensino e a pesquisa, quando discentes de Graduação têm acesso a projeto de pesquisa de docentes da instituição de ensino e podem atuar na produção científica (SOUZA COELHO FILHO et al., 2019). Ela tem como finalidade "despertar a vocação científica e incentivar talentos potenciais entre estudantes de graduação universitária, mediante participação em projeto de pesquisa, orientados por pesquisador qualificado" (BRASIL, 2006). Segundo dados do Ministério da Ciência, Tecnologia e Inovação (MCTI) ${ }^{3}$, entre 2001 e 2016 o Programa Institucional de Bolsas de Iniciação Científica (Pibic/CNPq) apresentou um crescimento do número de bolsas concedidas por ano de 14,5 mil para 22 mil, ou seja, um aumento de $51 \%$.

Estudos sinalizam (MASSI; QUEIROZ, 2010; CGEE, 2017; PINHO, 2017) as contribuições da iniciação científica para os discentes que dela participam, tais como: melhor desempenho na Graduação, desenvolvimento pessoal em relação às habilidades que são despertadas, maior integração entre a Graduação e a Pós-Graduação, formação de pesquisadores e docentes para universidades, entre outras. Palhano e Baptista (2016) enfatizam, ainda, o papel da pesquisa na formação docente, aproximando teoria e prática. Souza Junior e Amaro (2020) também encontraram indícios de que a iniciação científica leva à melhoria de competências sociais, de gestão, de resolução de problemas e de comunicação, contribuindo para uma formação completa.

A partir dos anos 1990, o Ensino Superior difundiu-se no Brasil e mudou significativamente; além disso, o Pibic consolidou-se como um programa permanente do Conselho Nacional de Desenvolvimento Científico e Tecnológico (CNPq), ampliando-se para todas as unidades da federação, diversas instituições de ensino e pesquisa, envolvendo milhares de alunos e orientadores e um vultoso volume de recursos financeiros investidos (CGEE, 2017). Pinho (2017) destaca a importância da inserção dos alunos de Graduação em programas de iniciação, posto que a atividade de pesquisa possibilita a realização das práticas de aprendizagens além do que é proposto na grade curricular do curso, e amplia a formação tanto acadêmica quanto profissional.

Na Universidade de Brasília (UnB) o Programa de Iniciação Científica (ProlC) é responsável pelas ações de iniciação científica, com o apoio financeiro de agências fomentadoras como o CNPq e a Fundação de Apoio à Pesquisa do Distrito Federal (FAPDF). Todos os anos são publicados três editais específicos destinados aos discentes e docentes do ensino de Graduação, a saber: Programa de Iniciação Científica (Pibic), Programa de Iniciação Científica em Desenvolvimento Tecnológico e Inovação (Pibiti) e Programa de Iniciação Científica nas Ações Afirmativas (Pibic-AF) ${ }^{4}$.

Os editais estabelecem regras relativas à participação dos potenciais beneficiários e docentes orientadores do Programa, aos procedimentos de inscrição, às etapas e critérios de seleção de candidaturas qualificadas, às diretrizes de fomento à concessão e compromissos dos docentes participantes e discentes beneficiários ao evento de iniciação científica e ao cronograma de atividades do Programa (UNB, 2011).

\footnotetext{
${ }_{3}^{3}$ Disponível em: http://aquarius.mcti.gov.br/app/. Acesso em: 4 set. 2019.

${ }^{4} \mathrm{O}$ Pibic-AF é restrito a alunos que ingressaram na UnB por sistemas de Ações Afirmativas - tanto por cotas sociais quanto raciais.
} 
$\mathrm{Na}$ literatura encontram-se diversos trabalhos que abordam as contribuições da iniciação científica para discentes de Instituições de Ensino Superior (IES), ora em cursos específicos, ora para a instituição como um todo. Nota-se, porém, uma limitação de estudos que trabalhem a temática de forma quantitativa (avaliação com índice econômico) e no âmbito da UnB. Nesse sentindo, este trabalho busca contribuir com a literatura ao utilizar métodos quantitativos de avaliação por meio de métodos poucos explorados nessa temática e uma avaliação sistemática do programa de iniciação científica - em especial o da UnB -, e auxiliar a instituição utilizada como objeto do estudo em possíveis tomadas de decisão e aperfeiçoamentos da execução da política.

O presente trabalho apresenta, assim, uma análise da concentração de beneficiários do ProlC - por docente orientador e unidades acadêmicas da UnB de 2004 a 2018. Utilizou-se o Índice de Herfindahl-Hirschman (HH). O HH é frequentemente utilizado para análise da concentração industrial, calculado pelo quadrado da participação do agente no programa. Esse é um índice bastante utilizado em contextos de organização industrial, ecologia, entre outros, para mensurar concentração, e já foi utilizado no contexto de concentração de pesquisa (KWOKA, 1985; ALEXANDER, 1996).

Este artigo está organizado em quatro seções, além desta introdução. A seção seguinte apresenta o marco conceitual da temática em estudo, trata da iniciação científica no contexto brasileiro e da instituição que será objeto deste estudo. A seção três apresenta a base de dados que será utilizada e a metodologia aplicada. A quarta seção traz os resultados obtidos, e a última conclui a análise discorrendo sobre as principais contribuições e limitações do estudo.

\section{A INICIAÇÃO CIENTÍFICA NO BRASIL}

Desde sua criação, o CNPq concedeu bolsas de iniciação científica aos estudantes de Graduação, posto que, inicialmente, o número de bolsas era altamente restrito e sua concessão ficava aos cuidados do pesquisador responsável por uma pesquisa apoiada pela instituição. Em meados dos anos 1970, apesar de um aumento no volume dessas bolsas, elas eram concedidas por meio de julgamento de mérito das propostas de projetos que eram apresentadas individualmente pelos candidatos e pelo perfil do docente orientador. A atribuição das bolsas voltou a ficar a cargo do pesquisador coordenador do projeto, que também era responsável pela indicação do aluno bolsista, a supervisão de seu trabalho e fortuitas substituições; tal formato de concessão era conhecido como atendimento "de balcão" (CGEE, 2017).

Em 1988, as bolsas de iniciação científica passaram a ser distribuídas por meio de cotas institucionais com a criação do Programa Institucional de Bolsas de Iniciação Científica do CNPq (PIBIC/CNPq), ou seja, uma nova modalidade de fomento, quando as bolsas passaram a ser concedidas diretamente às Instituições de Ensino Superior (IESs) e aos Institutos de Pesquisa (IPs). Essas instituições eram responsáveis por administrar diretamente as concessões dessas bolsas, ficando encarregadas de selecionar propostas de projetos, docentes orientadores e alunos beneficiários, seguindo critérios estabelecidos pelo $\mathrm{CNPq}$, bem como promover a organização de evento anualmente para apresentação dos resultados alcançados (MASSI; QUEIROZ, 2010; CGEE, 2017). Pires (2016) destaca que, apesar dos indícios de bons resultados dos programas de iniciação científica, esses sofreram estrangulamentos orçamentários ao longo dos anos. 
Nos anos 1990 duas avaliações foram produzidas no âmbito do Pibic (MARCUSCHI, 1996; ARAGÓN, 1999) e assinalaram os resultados relevantes obtidos pelo programa. Recentemente, mais um estudo de avaliação do Programa foi lançado - "A formação de novos quadros para CT\&I: avaliação do Programa Institucional de Bolsas de Iniciação Científica (Pibic)" (CGEE, 2017) -, e apontou, dentre os resultados relevantes para aqueles alunos beneficiários do programa, a redução do tempo de titulação do Mestrado e a maior chance de completar tanto o Mestrado quanto o Doutorado, quando comparados aos alunos que não foram beneficiários do programa. Tal nexo entre a entrada e Pós-Graduação e a futura publicação também foi evidenciado por Palheta e Lima (2019). Já Lima et al. (2018) também encontraram evidências positivas de que o programa contribui com uma maior produtividade científica.

O estudo de Dantas (2019), analisando o caso da UFRN, mostra que, além da influência da iniciação científica na progressão acadêmica para a Pós-Graduação, os egressos do programa obtiveram a titulação máxima mais jovens que os demais estudantes, assim como aqueles estudantes que participaram da iniciação científica por um maior tempo, que atingem uma maior qualificação na Pós-Graduação.

Em 1992, a UnB passou a participar do Pibic/CNPq, tendo instituído as cem bolsas que foram concedidas inicialmente (UNB, 1993). Já em 2009 criou-se o Regulamento do ProlC, tendo sido fruto da demanda por ampliação e consolidação da política interna voltada à pesquisa. Assim, o primeiro edital voltado a selecionar projetos de iniciação científica foi publicado em 2009 (BITTENCOURT, 2016).

Bittencourt (2016) fez uma análise exploratória da política de iniciação científica até então vigente, mas essa sofreu algumas alterações, buscando ampliar o acesso a novos orientadores, principalmente aqueles que nunca haviam participado do programa. Dessa forma, esse trabalho justifica-se buscando analisar se tais mudanças institucionais produziram o desejado efeito de desconcentração na orientação, ampliando o acesso ao programa.

\section{BASES DE DADOS E MÉTODO}

São publicados todos os anos, levando em consideração o ano acadêmico do ProlC, que compreende o período de agosto a julho, três editais específicos publicados pela UnB destinados aos discentes e docentes do ensino de Graduação, a saber: Pibic, Pibiti ${ }^{5}$ e Pibic-AF.

O ProlC estrutura-se com base em duas modalidades de fontes de fomento à iniciação científica. Conforme o Quadro $1^{6}$, é possível verificar as modalidades de fontes e uma breve análise dos Editais ProlC do período de 2009 a 2018. É necessário ressaltar o vínculo com as receitas orçamentárias da universidade, quando a quantidade de recursos leva a uma oferta maior ou menor da disponibilidade de remuneração aos projetos contemplados pelos editais.

\footnotetext{
5 O Edital Pibiti passou a integrar o ProlC em 2012.

${ }^{6}$ Editais disponíveis no site do ProlC até o momento da consulta. Disponível em: http://proic.unb.br/index.php?option=com_content\&view=article\&id=598\&Itemid=333. Acesso em: 7 ago. 2019.
} 
Quadro 1 - Linhas de Fomento do Programa de Iniciação Científica da UnB

\begin{tabular}{|c|c|c|}
\hline $\begin{array}{l}\text { Linhas de } \\
\text { Fomento }\end{array}$ & Linha 1 & Linha 2 \\
\hline Recursos & $\begin{array}{l}\text { Provenientes das agências de } \\
\text { fomento, em especial do CNPq, da } \\
\text { FAPDF e do MCTI. }\end{array}$ & $\begin{array}{l}\text { Do Decanato de Pós-Graduação (DPG/UnB), provenien- } \\
\text { tes do orçamento da UnB, que servem de contraparti- } \\
\text { da institucional aos recursos repassados pelas agências } \\
\text { de fomento para a iniciação científica. }\end{array}$ \\
\hline $\begin{array}{l}\text { Partici- } \\
\text { pantes }\end{array}$ & $\begin{array}{l}\text { Docentes do quadro permanente } \\
\text { e pesquisadores visitantes, em } \\
\text { efetivo exercício, com titulação } \\
\text { de doutor e com perfil produtivo, } \\
\text { conforme estabelece as normas } \\
\text { das agências de fomento. }\end{array}$ & $\begin{array}{l}\text { Docentes do quadro permanente, em efetivo exercício, } \\
\text { da UnB com titulação de doutor ou equivalente; } \\
\text { Excepcionalmente, docentes do quadro permanente } \\
\text { em efetivo exercício, da UnB com titulação de mestre; } \\
\text { Discente de Doutorado, com parecer favorável do } \\
\text { orientador(a), que tenha sido aprovado no exame de } \\
\text { qualificação do projeto tese ou o estágio sanduíche no } \\
\text { exterior ou no Brasil não coincidam com o ano acadê- } \\
\text { mico do ProlC. }\end{array}$ \\
\hline \multicolumn{3}{|c|}{ Análise dos Editais ProlC 2009-2018 } \\
\hline $2009-2010$ & $\begin{array}{l}100 \% \text { dos recursos distribuídos } \\
\text { para os participantes listados na } \\
\text { linha de fomento. }\end{array}$ & $\begin{array}{l}\text { - } 60 \% \text { das bolsas serão distribuídas com base na classi- } \\
\text { ficação final } \\
\text { decrescente das candidaturas na Categoria "Docente } \\
\text { Recém-Doutor/a"1; } \\
-40 \% \text { das bolsas serão distribuídas com base na classi- } \\
\text { ficação final decrescente das candidaturas na Categoria } \\
2 \text { "Professor Lotado nos Campi (FCE, FGA e FUP)". }\end{array}$ \\
\hline 2011-2012 & $\begin{array}{l}100 \% \text { dos recursos distribuídos } \\
\text { para os participantes listados na } \\
\text { linha de fomento. }\end{array}$ & $\begin{array}{l}\text { - } 40 \% \text { das bolsas serão distribuídas com base na classi- } \\
\text { ficação final } \\
\text { decrescente das candidaturas na Categoria "Docente } \\
\text { Recém-Doutor/a"1; } \\
\text { - 60\% das bolsas serão distribuídas com base na classi- } \\
\text { ficação final decrescente das candidaturas na Catego- } \\
\text { rias "Professor Lotado nos Campi", "Professor Mestre" } \\
\text { e "Discente Doutorando". }\end{array}$ \\
\hline $2013-2015$ & $\begin{array}{l}100 \% \text { dos recursos distribuídos } \\
\text { para os participantes listados na } \\
\text { linha de fomento. }\end{array}$ & $\begin{array}{l}\text { - } 20 \% \text { das bolsas serão distribuídas com base na clas- } \\
\text { sificação final decrescente das candidaturas para do- } \\
\text { centes da categoria "Docente Recém-Doutor/a" e da } \\
\text { categoria "Docente Mestre". }\end{array}$ \\
\hline $2016-2018$ & $\begin{array}{l}100 \% \text { dos recursos distribuídos } \\
\text { para os participantes listados na } \\
\text { linha de fomento. } \\
\text { Orientadores vinculados a mais de } \\
\text { um edital no Programa de Inicia- } \\
\text { ção Científica da UnB (Pibic, Pibiti, } \\
\text { Pibic-AF) não podem ultrapassar } 3 \\
\text { (três) bolsas no total. }\end{array}$ & $\begin{array}{l}\text { - } 20 \% \text { das bolsas serão distribuídas com base na classi- } \\
\text { ficação final decrescente das candidaturas para orien- } \\
\text { tadores da categoria "Docente Recém-Doutor/a" e da } \\
\text { categoria “Docente Mestre". } \\
\text { Orientadores vinculados a mais de um edital no Pro- } \\
\text { grama de Iniciação Científica da UnB (Pibic, Pibiti, Pibi- } \\
\text { c-AF) não podem ultrapassar três bolsas no total. }\end{array}$ \\
\hline
\end{tabular}

Nota: ${ }^{1}$ Segundo os editais ProlC, recém-doutor é aquele que obteve o título de doutor há no máximo quatro anos.

Fonte: Elaboração própria.

Quanto aos critérios de seleção das candidaturas, os editais de 2009 a 2017 avaliaram os seguintes parâmetros: produção científica, tecnológica ou artístico-cultural recente, divulgada nos principais veículos de comunicação da área, relatada no Currículo Lattes (CV Lattes) e mérito científico da proposta de pesquisa, posto que cada parâmetro conta com diversos itens para pontuação. 
Os editais ProlC referentes aos períodos de 2017 e, principalmente, 2018, sofreram alterações quanto às diretrizes do fomento e critérios de seleção de docentes orientadores. Tais mudanças resultaram em uma análise mais atenciosa dos projetos e planos de pesquisas que concorreram aos editais, de forma a balancear o peso que é dado aos currículos ${ }^{7}$. A motivação para as alterações deve-se ao fato de que, assim, os docentes com excelentes currículos continuariam a ser contemplados, e o aumento na quantidade de bolsas e sua melhor distribuição possibilitaria a inserção de novos profissionais.

O banco de dados do ProlC foi disponibilizado pelo ProlC vinculado ao DPG/UnB, e a relação dos docentes da UnB foi disponibilizada em formato aberto no sítio do Decanato de Gestão de Pessoas (DGP/UnB). O banco de dados da iniciação científica provê informações dos discentes beneficiários do ProlC e docentes orientadores que abrangem o período de agosto/2004 a julho/2019. Já a relação ${ }^{8}$ dos docentes fornece diversas informações do registro funcional. Para este estudo, foi utilizada a versão acessada em maio/2019, uma vez que as bases são atualizadas mensalmente.

As variáveis disponibilizadas e empregadas para a análise são aquelas relacionadas aos editais (Edital e Ano do Edital), docentes (Identificador do Docente e Unidade Administrativa ou Acadêmica de Lotação) e discentes (Identificador do Aluno e Tipo de Participação).

A seguir, a Tabela 1 apresenta a distribuição de docentes, discentes e unidades acadêmicas $^{9}$ que estiveram envolvidas no ProlC durante o período analisado. $O$ edital Pibic, por ser o pioneiro e mais consolidado, é o que mais contempla alunos beneficiários e docentes orientadores, além de ser o que mais abrange unidades acadêmicas da universidade. Ressalta-se que o número de discentes beneficiários do Pibic com participação remunerada foi maior que os voluntários até o ano de 2012, e a partir de 2013 há uma inversão entre renumerados e voluntários em razão da restrição de recursos para bolsas remuneradas e não restrição de vagas para voluntários (o número de vagas depende de projetos de qualidade).

Já os editais Pibiti e Pibic-AF, por serem mais específicos em sua área e público, respectivamente, possuem um menor quantitativo de bolsas disponibilizadas quando comparados ao Pibic, e, consequentemente, um menor envolvimento de discentes, docentes e unidades acadêmicas.

Tabela 1 - Total de Beneficiários por Tipo de Edital - ProlC, 2004-2018

\begin{tabular}{ccccccccccccccccc}
\hline Ano & \multicolumn{1}{c}{ PIBIC } & \multicolumn{1}{c}{ PIBIC - AF } & \multicolumn{1}{c}{ PIBITI } \\
\hline & $\mathrm{T}$ & $\mathrm{R}$ & $\mathrm{V}$ & $\begin{array}{c}\text { Orien- } \\
\text { tadores }\end{array}$ & $\mathrm{UA}$ & $\mathrm{T}$ & $\mathrm{R}$ & $\mathrm{V}$ & $\begin{array}{c}\text { Orien- } \\
\text { tadores }\end{array}$ \\
2004 & 656 & 483 & 173 & 266 & 27 & - & - & - & - & - & - & - & - & - & - \\
2005 & 679 & 397 & 282 & 260 & 27 & 20 & 20 & - & 8 & 5 & - & - & - & - & - \\
2006 & 769 & 449 & 320 & 273 & 29 & 9 & 9 & - & 6 & 4 & - & - & - & - & - \\
tadores
\end{tabular}

\footnotetext{
7 Disponível em: https://noticias.unb.br/publicacoes/67-ensino/1652-balanco-da-iniciacao-cientifica-registra-mais-oportunidades-para-docentes-e-estudantes. Acesso em: 10 nov. 2018.

8 Disponível em: http://dgp.unb.br/dados-abertos. Acesso em: 15 maio 2019.

${ }^{9}$ Para os docentes vinculados a atividades de gestão, na data de acesso à base, considerou-se a unidade administrativa de lotação.
} 


\begin{tabular}{ccccccccccccccccc}
2007 & 901 & 479 & 422 & 333 & 27 & - & - & - & - & - & - & - & - & - & - \\
2008 & 840 & 530 & 310 & 318 & 29 & 9 & 9 & - & 5 & 4 & - & - & - & - & - \\
2009 & 927 & 662 & 265 & 364 & 27 & 34 & 29 & 5 & 25 & 12 & - & - & - & - & - \\
2010 & 1.167 & 752 & 415 & 490 & 30 & 40 & 31 & 9 & 30 & 14 & - & - & - & - & - \\
2011 & 1.763 & 1.071 & 692 & 635 & 29 & 51 & 26 & 25 & 34 & 15 & - & - & - & - & - \\
2012 & 2.149 & 1.092 & 1.057 & 750 & 30 & 67 & 33 & 34 & 49 & 16 & 155 & 60 & 95 & 70 & 19 \\
2013 & 2.451 & 1.164 & 1.287 & 818 & 30 & 44 & 32 & 12 & 27 & 16 & 127 & 72 & 55 & 61 & 14 \\
2014 & 2.088 & 904 & 1.184 & 703 & 29 & 91 & 40 & 51 & 51 & 22 & 149 & 66 & 83 & 68 & 16 \\
2015 & 2.438 & 1.171 & 1.267 & 849 & 30 & 73 & 41 & 32 & 50 & 24 & 154 & 75 & 79 & 66 & 15 \\
2016 & 2.662 & 1.068 & 1.594 & 922 & 29 & 73 & 52 & 21 & 50 & 20 & 142 & 70 & 72 & 66 & 16 \\
2017 & 2.563 & 1.09 & 1.473 & 908 & 29 & 119 & 74 & 45 & 82 & 20 & 202 & 106 & 96 & 99 & 20 \\
2018 & 2.281 & 675 & 1.606 & 934 & 30 & 196 & 49 & 147 & 129 & 24 & 110 & 45 & 65 & 73 & 18 \\
\hline
\end{tabular}

T - Total de alunos; V - Voluntário; R - Remunerado; UA - Unidade Acadêmica.

Fonte: Elaboração Própria.

\section{O Índice de concentração de Hirschman-Herfindahl}

Segundo Hoffmann (1982), o índice de concentração de HH frequentemente é utilizado para análise da concentração industrial. A revisão de literatura permitiu que fossem identificados estudos em que seus autores utilizaram o índice em diferentes contextos: Lim (2004) avaliou o impacto da pesquisa básica e aplicada sobre inovação; Quintana-Garca e Benavides-Velasco (2008) investigaram a diversificação tecnológica e sua influência na taxa e nos tipos específicos de competência inovadora; Tseng et al. (2013) utilizaram o índice HH para auxiliar a quantificar dados de produção científica e assim fazer uma avaliação cientométrica. O presente estudo aplicará o índice para analisar a concentração de discentes beneficiários do Programa de Iniciação Científica em uma instituição de ensino (UnB).

Dessa forma, considere que $X$ seja a variável que assume o valor da quantidade de discentes beneficiários da iniciação científica de uma instituição de ensino. Supõe-se que o universo dos docentes orientadores de projetos de iniciação científica seja dividido em $k$ grupos (unidades, por exemplo). Seja $n_{h}(\operatorname{com} h=1, \ldots, k)$ o número de docentes orientadores no $\underline{h}$-ésimo grupo e seja $X_{h i}\left(\operatorname{com} h=1, \ldots, k\right.$ e $\left.i=1, \ldots, n_{h}\right)$ o valor da quantidade de discentes beneficiários do ì-ésimo docente do $\underline{h}$-ésimo grupo. $O$ número total de docentes orientadores da instituição de ensino é

$$
N=\sum_{h=1}^{k} n_{h}
$$

Se o valor médio da quantidade de discentes beneficiários por docente orientador é $\mu$, a fração do valor total da quantidade de discentes beneficiários da instituição de ensino que corresponde ao i-ésimo docente do $\underline{h}$-ésimo grupo é

$$
Y_{h i}=\frac{X_{h i}}{N_{\mu}}
$$

A proporção de docentes que pertence ao $\underline{h}$-ésimo grupo é

$$
\pi_{h}=\frac{n_{h}}{N}
$$


e a correspondente proporção do valor total da quantidade de discentes beneficiários do programa de iniciação científica da instituição de ensino é

$$
Y_{h}=\sum_{i=1}^{n_{h}} Y_{h i}
$$

O valor médio da quantidade de discentes beneficiários por docente orientador no $\underline{h}$-ésimo grupo é

$$
\mu_{h}=\frac{1}{n_{h}} \sum_{i=1}^{n_{h}} X_{h i}=\frac{Y_{h}}{\pi_{h}} \mu
$$

Por fim, o Índice de Herfindahl-Hirschman para instituição de ensino é definido por

$$
H H=\sum_{h=1}^{k} \sum_{i=1}^{n_{h}} Y_{h i}^{2}
$$

O valor do índice varia entre $\frac{1}{N} \leq H H \leq 1$ (quando $X_{h i}>0$ ), posto que $\mathrm{HH}$ alcança seu valor mínimo ou máximo, respectivamente, quando todos os valores de $\underline{X}$ são iguais a $\mu$ ou quando um dos valores de $\underline{X}$ é igual a $\mathrm{N}_{\mu}$ e todos os outros são iguais a zero. Quanto mais próximo o índice for de zero indica uma menor concentração; caso o índice se aproxime de 1 indica uma elevada concentração.

Como consideraremos tanto a concentração referente à participação dos discentes beneficiários em projetos de iniciação científica remuneradas quanto voluntárias, trabalharemos, respectivamente, com dois índices: $H H_{r}$ e $H H_{V}$.

Resende (1994) ressalta uma limitação quanto ao índice $H H$, no qual as comparações intertemporais ficam prejudicadas à medida que o número de unidades acadêmicas ou docentes orientadores altera, pois o limite inferior $\left(\frac{1}{n}\right)$ também se altera. Desta maneira, faz-se necessário ajustes nos índices quando o número de unidades acadêmicas ou docentes orientadores estiver variando ao longo do período estudado.

Os índices de $H H_{r}$ e $H H_{V}$ podem ser ajustados acerca da amplitude de variação, definidos por:

$$
\begin{aligned}
& H H_{r}^{\prime \prime}=\frac{1}{n-1}\left[n H H_{r}-1\right] \\
& H H_{v}^{\prime \prime}=\frac{1}{n-1}\left[n H H_{v}-1\right]
\end{aligned}
$$

Assim, a proporção que o índice se distancia de zero maior será a concentração. Se a variação acontecer no intervalo $0 \leq H H^{\prime \prime}<0,1$, caracteriza-se como desconcentrado. O intervalo $0,1 \leq H H^{\prime \prime} \leq 0,18$ indica pouca concentração. Quando, porém, o $H H^{\prime \prime}>0,18$ há uma concentração elevada (RESENDE; BOFF, 2002).

\section{RESULTADOS}

A fim de verificar o comportamento da concentração da distribuição de discentes beneficiários do Programa de Iniciação Científica da Universidade de Brasília entre 2004 e 2018, a Tabela 2 apresenta a evolução dos índices, construídos com base no número de discentes beneficiários e unidade acadêmica dos docentes orientadores, considerando o edital, o tipo de participação e o ano do edital. 
Tabela 2 - Índice referente à unidade acadêmica a que o docente orientador está vinculado, por edital e ano do edital, 2004-2018

\begin{tabular}{|c|c|c|c|c|c|c|c|}
\hline \multicolumn{4}{|c|}{ Índice } & \multicolumn{4}{|c|}{ Índice } \\
\hline $\begin{array}{c}\text { Ano do } \\
\text { Edital }\end{array}$ & Pibic & Pibic-AF & Pibiti & $\begin{array}{l}\text { Ano do } \\
\text { Edital }\end{array}$ & Pibic & Pibic-AF & Pibiti \\
\hline 2004 & 0,099 (D) & - & - & 2004 & 0,072 (D) & - & - \\
\hline 2005 & $0,083(D)$ & 0,216 (C) & - & 2005 & 0,079 (D) & - & - \\
\hline 2006 & 0,082 (D) & $0,250(\mathrm{C})$ & - & 2006 & 0,066 (D) & - & - \\
\hline 2007 & 0,092(D) & - & - & 2007 & 0,060 (D) & - & - \\
\hline 2008 & $0,075(D)$ & $0,250(C)$ & - & 2008 & 0,061 (D) & - & - \\
\hline 2009 & 0,069 (D) & $0,150(P C)$ & - & 2009 & $0,058(D)$ & $0,100(P C)$ & - \\
\hline 2010 & 0,066 (D) & $0,065(D)$ & - & 2010 & $0,064(D)$ & $0,083(D)$ & - \\
\hline 2011 & $0,068(D)$ & $0,068(D)$ & - & 2011 & 0,060 (D) & $0,213(C)$ & - \\
\hline 2012 & $0,064(D)$ & $0,070(D)$ & 0,090(D) & 2012 & 0,057 (D) & $0,150(P C)$ & $0,110(P C)$ \\
\hline 2013 & 0,066 (D) & $0,087(\mathrm{D})$ & $0,117(\mathrm{PC})$ & 2013 & 0,062 (D) & $0,106(P C)$ & $0,159(P C)$ \\
\hline 2014 & $0,065(D)$ & $0,063(\mathrm{D})$ & $0,205(C)$ & 2014 & 0,069 (D) & $0,115(P C)$ & $0,118(P C)$ \\
\hline 2015 & 0,060(D) & $0,043(D)$ & $0,151(P C)$ & 2015 & 0,065 (D) & $0,065(D)$ & 0,080 (D) \\
\hline 2016 & $0,063(D)$ & $0,050(D)$ & $0,117(P C)$ & 2016 & $0,064(D)$ & $0,148(P C)$ & $0,134(P C)$ \\
\hline 2017 & 0,058 (D) & $0,067(D)$ & 0,081(D) & 2017 & 0,062 (D) & 0,093(D) & $0,118(\mathrm{PC})$ \\
\hline 2018 & $0,068(D)$ & 0,070 (D) & $0,111(P C)$ & 2018 & 0,058 (D) & $0,063(D)$ & 0,089 (D) \\
\hline
\end{tabular}

Fonte: Elaboração Própria. D - desconcentrado; PC - pouca concentração; C - alta concentração.

Nota-se que a concentração média atinge valor máximo de 0,250 (no edital Pibic-AF, remunerado), indicando concentração. Ao avaliar, entretanto, os índices por edital e ano, percebem-se comportamentos distintos.

Ao verificar a participação tanto remunerada quanto voluntária e a unidade acadêmica do docente que orientou o projeto, observa-se que o Pibic é o edital com maior evidência de baixa concentração. Observa-se que, em todos os anos analisados, seu índice de concentração é o menor dentre os editais e em todos os anos esse índice registrou desconcentração. Esse resultado justifica-se em virtude das especificidades dos editais Pibic-AF e Pibiti. No caso do Pibiti, não são todas as linhas de pesquisa e, portanto, docentes (ou até mesmo unidades acadêmicas) que se enquadram ao perfil de pesquisa proposto a esse edital, pois as propostas de pesquisa devem estar vinculadas, prioritariamente, aos objetos desenvolvidos pelas empresas incubadas e em incubação em atuação no Núcleo de Inovação Tecnológica do Centro de Apoio ao Desenvolvimento Tecnológico - NIT/CDT - ou pelas empresas do Parque Científico e Tecnológico da UnB, ou a apresentação dos projetos deve adequar-se às sugestões de temas, o que faz com que sua concentração em relação às unidades acadêmicas se eleve. Já no caso do Pibic-AF, trata-se de um edital com um número reduzido de bolsas em relação aos demais e que ainda está em consolidação, dada a criação de políticas de ação afirmativas de forma extensiva na universidade a partir da Lei de Cotas no 12.711 de 2012. Esse tipo de edital apresentou maior concentração principalmente na época de seu lançamento, porém, após isso, o índice mostrou apenas valores associados à desconcentração quando analisada a distribuição de bolsas remuneradas. No caso da concentração associada 
à participação voluntária, observa-se uma concentração maior, que pode estar associada a um viés de seleção dos participantes dispostos a submeter ao edital, uma vez que não há restrições de vagas.

Na Tabela 3, a seguir, destacam-se os índices de concentração, construídos com base no número de discentes beneficiários e docentes orientadores, considerando o edital, o tipo de participação e o ano do edital. A principal diferença em relação a essa análise e à anterior é que o número de projetos por docente geralmente é limitado, tanto do ponto de vista remunerado quanto voluntário.

Tabela 3 - Índice referente ao docente e orientador, por edital e ano do edital, 2004-2018

\begin{tabular}{|c|c|c|c|c|c|c|c|}
\hline \multicolumn{4}{|c|}{ Índice } & \multicolumn{4}{|c|}{ Índice } \\
\hline $\begin{array}{l}\text { Ano do } \\
\text { Edital }\end{array}$ & Pibic & Pibic-AF & Pibiti & $\begin{array}{c}\text { Ano do } \\
\text { Edital }\end{array}$ & Pibic & Pibic-AF & Pibiti \\
\hline 2004 & 0,004 (D) & - & - & 2004 & $0,005(D)$ & - & - \\
\hline 2005 & $0,003(D)$ & $0,163(P C)$ & - & 2005 & $0,005(D)$ & - & - \\
\hline 2006 & $0,003(D)$ & $0,083(D)$ & - & 2006 & $0,004(D)$ & - & - \\
\hline 2007 & $0,003(D)$ & - & - & 2007 & $0,004(D)$ & - & - \\
\hline 2008 & $0,002(D)$ & $0,167(P C)$ & - & 2008 & $0,004(D)$ & - & - \\
\hline 2009 & $0,002(D)$ & $0,022(D)$ & - & 2009 & $0,004(D)$ & $0,000(D)$ & - \\
\hline 2010 & $0,002(D)$ & $0,013(D)$ & - & 2010 & $0,003(D)$ & $0,000(D)$ & - \\
\hline 2011 & $0,001(D)$ & 0,006 (D) & - & 2011 & $0,002(D)$ & $0,043(D)$ & - \\
\hline 2012 & $0,001(D)$ & $0,004(D)$ & $0,008(D)$ & 2012 & $0,002(D)$ & $0,025(D)$ & $0,013(D)$ \\
\hline 2013 & $0,001(D)$ & $0,024(D)$ & $0,011(D)$ & 2013 & $0,002(D)$ & $0,061(D)$ & $0,030(D)$ \\
\hline 2014 & $0,001(D)$ & 0,009 (D) & $0,028(D)$ & 2014 & $0,002(D)$ & $0,013(D)$ & $0,013(D)$ \\
\hline 2015 & $0,001(D)$ & $0,005(D)$ & $0,012(D)$ & 2015 & $0,002(D)$ & $0,030(D)$ & $0,022(D)$ \\
\hline 2016 & $0,001(D)$ & 0,007 (D) & $0,010(D)$ & 2016 & $0,002(D)$ & $0,048(D)$ & $0,026(D)$ \\
\hline 2017 & $0,001(D)$ & 0,000 (D) & $0,004(D)$ & 2017 & $0,002(D)$ & $0,017(D)$ & $0,027(D)$ \\
\hline 2018 & $0,001(D)$ & $0,003(\mathrm{D})$ & $0,005(D)$ & 2018 & $0,001(D)$ & $0,007(D)$ & $0,013(\mathrm{D})$ \\
\hline
\end{tabular}

De modo similar ao índice referente à unidade acadêmica, observa-se que a concentração média que diz respeito ao docente orientador atinge valor máximo de 0,167 (no edital Pibic-AF, remunerado), sinalizando pouca concentração agora. Ou seja, a restrição de projetos por docentes auxilia a não concentrar projetos e bolsas, ainda que algumas unidades sejam mais especializadas nesse tipo de atividade científica.

Diferentemente do que ocorria com os dados de unidades, não se observa a alta concentração entre os docentes orientadores no edital Pibiti nem entre os docentes orientadores no edital Pibic-AF, reforçando que o problema de concentração que se observa na Tabela anterior não é associado a docentes específicos, mas às áreas de pesquisa e unidades acadêmicas em que eles atuam.

Em síntese, quando considerados os gráficos e tabelas de forma conjunta, há algumas observações a serem feitas:

Como já observado, o grau de concentração para o edital Pibic é muito inferior aos demais editais, fato que, provavelmente, está relacionado com seu tradicionalismo na Universidade, tamanho e consequente alcance. Além disso, mesmo que variáveis, 
seus níveis de concentração são muito mais estáveis do que os dos demais programas. Essas duas características - baixo nível de concentração e aparente estabilidade - indicam que, mesmo que haja pequenas concentrações, o programa parece ser bastante difundido na Universidade.

Em segundo lugar, apesar de apresentar essa baixa e estável concentração quando analisado com mais detalhe, observa-se que os níveis de concentração do Pibic, seja por docente ou por unidade, mostraram queda durante o período observado, sugerindo que os esforços realizados de diversificar o acesso ao programa parecem ter apresentado efeito.

A análise da concentração da distribuição de discentes beneficiários, tanto por unidade acadêmica quanto por docente orientador, quando considerada a participação remunerada, seguem comportamento similar. É importante salientar, porém, que a distribuição por docentes orientadores apresenta um formato mais achatado em razão de o índice mostrar valores menores (ou seja, uma menor concentração), posto que isto tem forte relação com a quantidade de grupos que foram considerados para cada índice, uma vez que existe um número significativamente maior de docentes do que de unidades.

Com referência à participação voluntária no ProlC, essa não depende de uma restrição orçamentária de recursos e sim de uma restrição do interesse e da qualidade dos projetos submetidos (ou seja, se muitos projetos bons forem submetidos, muitos voluntários serão contemplados). Nesse caso, aqueles docentes que pleiteiam bolsas remuneradas para seus discentes, mas não são bem sucedidos na concorrência, podem aderir ao programa por meio da participação voluntária. Nessa perspectiva, a concentração varia ao longo do tempo exceto por efeito de outliers, principalmente no caso do edital de Ações Afirmativas em que há menos docentes.

\section{COMENTÁRIOS FINAIS}

O presente estudo buscou analisar a concentração da distribuição de discentes beneficiários do ProlC por docente orientador e unidades acadêmicas na UnB entre 2004 e 2018, por meio do Índice de HH adaptado para o contexto de uma instituição de ensino. Para tal, utilizou-se a base de dados do ProlC disponibilizada pelo ProlC e a relação dos docentes da UnB disponibilizada em formato aberto no sítio do DGP/UnB.

A análise sinalizou uma concentração não elevada em geral, porém com diferentes comportamentos a depender do ano e do edital. O edital Pibic foi o edital com menor concentração, enquanto o edital Pibic-AF apresentou concentração elevada principalmente nos primeiros anos. A concentração, nesse período, justifica-se pela efetivação recente da política de cotas raciais na UnB e, assim, poucas bolsas foram ofertadas nessa modalidade no período. Além disso, poucos docentes envolveram-se na atividade de iniciação científica por meio dos editais Pibic-AF. Nota-se que, após o ano de 2010, o índice para o edital de Ações Afirmativas mostra-se relativamente constante e de menor concentração. Em relação ao edital Pibiti, a média do índice de concentração, mais alta, parece estar relacionada com seu caráter mais específico a determinados cursos. 
Percebe-se que a questão da concentração de discentes beneficiários pode, eventualmente, ser balizada pelos fatores que compõem o instrumento institucional utilizado para selecionar os participantes do ProlC na UnB, que acabam limitando ou disciplinando a atuação, principalmente, dos docentes que pleiteiam participar da atividade de pesquisa por meio do programa.

Dentre os editais analisados, o edital Pibic é o que apresenta menor nível de concentração e maior estabilidade ao longo dos anos, tanto para a participação remunerada quanto para a voluntária, o que evidencia uma maior difusão na Universidade, além de diversificação do acesso ao programa.

Em uma análise conjunta de todos os editais e tipos de participação, observou-se uma maior restrição na participação, ou seja, quanto menor o número de vagas para aquele edital (por exemplo, bolsas remuneradas são restritas; e menor número de vagas para Pibiti e Pibic-AF) maior tende a ser a concentração, sugerindo a presença de docentes e unidades "especialistas" nesses editais mais restritos. Quer dizer, a ampliação de vagas parece ter um efeito benéfico sobre a desconcentração da atividade de iniciação científica na universidade. Nesse sentido, há indícios de que um fortalecimento do programa em termos de vagas beneficiaria a universidade como um todo, possibilitando maior inserção de discentes, docentes orientadores e unidades acadêmicas, agregando, assim, sustentabilidade ao processo de renovação e expansão do efetivo de pesquisadores da instituição, conforme espera-se do programa.

Esse resultado é bastante interessante em um momento de discussão de distribuição de recursos à pesquisa em geral no país, sugerindo que regras restritivas a algumas áreas ou linha de pesquisa podem levar à concentrações que restringem o acesso de pesquisadores, criando nichos de especialistas ou até reservas de mercado para alguns, prejudicando a meritocracia na ciência.

\section{REFERÊNCIAS}

ALEXANDER, P. Entropy and popular culture: product diversity in the popular music recording industry. American Sociological Review. v. 61, n. 1, p. 171-174, 1996.

ARAGÓN, V. (coord.). O Programa Institucional de Bolsas de Iniciação Científica - Pibic - e sua relação com a formação de cientistas. Brasília: Nesub; UnB, 1999.

BITTENCOURT, D. Iniciação científica na Universidade de Brasilia: uma análise da política institucional no período 2011-2013. 2017. 118 f. Dissertação (Mestrado Profissional em Educação) - Universidade de Brasília, Brasília, DF, 2016.

BRASIL. Ministério da Ciência e Tecnologia. Conselho Nacional de Desenvolvimento Científico e Tecnológico. Anexo II da RN-017/2006 - Bolsas por quota no país. Programa Institucional de Bolsas de Iniciação Científica - Pibic - Norma Específica. Brasília, DF, 2006. Disponível em: http://www.cnpq.br/view/-/journal_content/56_INSTANCE_0oED/10157/100352. Acesso em: 10 nov. 2018.

BRASIL. Lei $n=12.711$ de 29 de agosto de 2012. Dispõe sobre o ingresso nas universidades federais e nas instituições federais de ensino técnico de nível médio e dá outras providências. Disponível em: http:// www.planalto.gov.br/ccivil_03/_ato2011-2014/2012/lei/l12711.htm Acesso em: 25 set. 2020.

CARVALHO, A. O Pibic e a difusão da carreira científica na universidade brasileira. 2002. Dissertação (Mestrado em Sociologia) - Universidade de Brasília, Brasília, DF, 2002.

CGEE. Centro de Gestão e Estudos Estratégicos. A Formação de novos quadros para CT\&I: avaliação do Programa Institucional de Bolsas de Iniciação Científica (Pibic). Brasília, DF, 2017. Disponível em: https:// www.cgee.org.br/documents/10195/734063/PIBIC_relatorio_completo.pdf/259e9590-08fc-40a6-9c1c-86646a6132e3?version=1.0. Acesso em: 11 nov. 2018. 
DANTAS, E. Formação de recursos humanos para pesquisa: avaliação do impacto do Programa Institucional de Bolsas de Iniciação Científica na Pós-Graduação da UFRN. 2019. 86f. Dissertação (Mestrado Profissional em Gestão de Processos Institucionais) - Universidade Federal do Rio Grande do Norte, Centro de Ciências Humanas, Letras e Artes, Natal, 2019.

HOFFMANN, R. A decomposição do índice de Hirschman-Herfindahl. Brazilian Review of Econometrics, Rio de Janeiro, v. 2, n. 2, p. 127-134, nov. 1982.

KWOKA, J. The Herfindahl index in theory and practice. Antitrust Bulletin, v. 30, 1985.

LIM, K. The relationship between research and innovation in the semiconductor and pharmaceutical industries (1981-1997). Research Policy, v. 33, p. 287-321, mar. 2004.

LIMA, L.; OLIVEIRA, J.; PIOTTO, H.; CARVALHO, R.; SOUZA, D. Influência da Iniciação Científica sobre a Pós-Graduação: um estudo de caso sobre tempo, idade de titulação e produção científica. CONGRESO INTERNACIONAL DE EDUCACIÓN Y APRENDIZAJE, 2018. Anais [...]. 2018.

MARCUSCHI, L. A. Avaliação do Programa Institucional de Bolsas de Iniciação Científica (PIBIC) do CNPq e Propostas de Ação. Recife: Ufpe, 1996.

MASSI, L.; QUEIROZ, S. Estudo sobre iniciação científica no Brasil: uma revisão. Cadernos de Pesquisa, São Paulo, v. 40, n. 139, p. 173-197, jan./abr. 2010.

PALHANO, T.; BAPTISTA, M. Ensino e pesquisa e a dicotomia e a transmissão e investigação na formação do professor. Revista Temas em Educação, v. 25, 2016.

PALHETA, R.; LIMA, A. A experiência da Iniciação Científica para a formação professional. CONGRESO INTERNACIONAL DE TECNOLOGÍAS EN LA EDUCACIÓN, 2019. Anais [...]. 2019.

PINHO, M. Ciência e ensino: contribuições da iniciação científica na educação superior. Avaliação, Campinas, v. 22, n. 3, p. 658-675, 2017.

PIRES, R. Iniciação científica e avaliação na educação superior brasileira. REXE-Revista de Estudios y Experiencias en Educación, v. 5, n. 1, p. 137-60, 2016.

QUINTANA-GARCA, C.; BENAVIDES-VELASCO, C. Innovative competence, exploration and exploitation: the influence of technological diversification. Research Policy, v. 37, p. 492-507, 2008.

RESENDE, M. Medidas de concentração industrial: uma resenha. Revista Análise Econômica, Porto Alegre, v. 12, n. 21, p. 24-33, 1994.

RESENDE, M; BOFF, H. Concentração industrial. In: KUPFER, D.; HASENCLEVER, L. (org.). Economia industrial: fundamentos teóricos e práticas no Brasil. Rio de Janeiro: Elsevier, 2002. p. 73-90.

SOUZA COELHO FILHO, M.; BOAS, T.; OLIVEIRA, L.; SILVA, R. Pesquisa científica na formação inicial de professores num curso de Licenciatura em uma instituição de Ensino Superior. Brazilian Journal of Development, v. 5, n. 2, p. 1.746-1.761, 2019.

SOUZA JUNIOR, R.; AMARO, R. Aprendizagem de competências além da sala de aula: o papel dos programas extracurriculares. Desenvolvimento em Questão, v. 18, n. 52, 2020.

TSENG, Y.; CHANG, C.; TUTWILER, M.; LIN, M.; BARUFALDI, J. A scientometric analysis of the effectiveness of Taiwan's educational research projects. Scientometrics, v. 95, n. 3, p. 1.141-1.166, 2013.

UNB. Universidade de Brasília. SEMINÁRIO DE PESQUISA DA UNB - GRADUAÇÃO E PÓS-GRADUAÇÃO: VOCÊ PESQUISA? ENTÃO... MOSTRE!, 2., 1993, Brasília. Anais [...]. Brasília: UnB, 1993.

UNB. Universidade de Brasília. Decanato de Pesquisa e Pós-Graduação. Resolução da CPP N.001/2011. Brasília: UnB, 2011. 